\title{
Effects of Hydraulic Gradient Variation on the Structure and Strength of a Compacted Tropical Soil
}

\author{
W.G. Silva, H.N. Pitanga, T.O. Silva, S.L.S. Dias Neto, D.C. Lima, T.P. Trindade
}

\begin{abstract}
Tropical soils have been extensively studied to evaluate the technical feasibility of their application in hydraulic earthworks such as compacted clay barriers in landfills. In these earthworks, the water flow in the porous medium generates percolation forces that can promote structural changes in the soil, with possible deleterious repercussions on its mechanical and hydraulic properties. In this context and considering the geotechnical peculiarities of tropical soils, this research aimed to characterize the influence of the hydraulic gradient used in column percolation tests on the structure of a compacted tropical soil and, therefore, on its shear strength. Compacted test specimens were subjected to water percolation tests and then to direct shear tests. Thin sections were removed from the compacted layers for micromorphological analysis. The results showed that, statistically, at $5 \%$ probability level, no significant variation in the overall mean shear strength and in the micromorphological features was found as a function of the applied hydraulic gradients. In general, the non-statistically significant change in soil structure also justifies the lack of significant variability on shear strength. The research highlights the importance of micromorphological analysis supported by statistics in understanding the structural aspects of compacted soils responsible for their engineering behaviors.
\end{abstract}

Keywords: compacted tropical soil, hydraulic gradient, micromorphological analysis, shear strength, statistical analysis.

\section{Introduction}

Brazilian standard NBR 8419 (ABNT, 1996) defines landfill as a method of final disposal of solid waste in the soil, which must operate using engineering principles in such a way as to confine the solid waste in the smallest possible volume without causing damage or threats to health, safety, and the environment. As a result of this definition and in order to classify a solid waste disposal site as a landfill, Vertematti (2015) pointed out that it must have waterproofing devices at both the base and the top, intermediate layers for coverage, subsurface drainage, internal drainage of gases and leachate, and surface water drainage.

The present research focused mainly on studying engineering properties of hydraulic barriers for the composition of landfill bases, which have been the object of numerous studies aimed at characterizing their most relevant properties, considering the appropriate use and their good functional performance in such geoenvironmental works (Daniel \& Wu, 1993; Benson et al., 1994).

Tropical soils have been extensively studied to evaluate the technical feasibility of their application in such constructions, mainly considering the geotechnical peculiarities of these materials compared to the soils of temperate regions. According to Wesley (1990) and Benatti et al. (2013), residual soils can be misleadingly evaluated as problematic soils just because some of their behavioral aspects do not conform to those of typical sedimentary soils considered suitable for engineering purposes.

Considering the potential of tropical soils to be applied in hydraulic barriers of landfills, there are the examples of studies by Ola (1980), Galvão et al. (2004), Taha \& Kabir (2005), Osinubi \& Nwaiwu (2006), Frempong \& Yanful (2008), Bello (2011), and Kundiri et al. (2016). In general, the primary concern of those studies is the influence of the following variables on the strength, rigidity, and permeability properties of these compacted soils destined for landfills: degree of saturation, moisture and compaction energy, soil structure, chemical composition, mineralogical composition, drying shrinkage potential, clay content and chemical stabilization.

From Classical Soil Mechanics, based on sedimentary soils formed in temperate regions, it is known that the velocity of percolation of a liquid in the soil can promote structural changes in the soil, with possible repercussions on its mechanical and hydraulic properties (Fox,1996; Kaoser et al., 2006; Ke \& Takahashi, 2012, 2014; Al-Taie et al., 2014).

Based on geotechnical peculiarities of the tropical soils, there is interest in evaluating the possible influence of the percolation rate used in column percolation tests on soil

Weiner Gustavo Silva, M.Sc., Assistant Professor, Centro de Ciências Exatas e Tecnológicas, Universidade Federal do Recôncavo da Bahia, Cruz das Almas, BA, Brazil. e-mail: weiner.ufrb@gmail.com.

Heraldo Nunes Pitanga, Ph.D., Associate Professor, Departamento de Engenharia Civil, Universidade Federal de Viçosa, Viçosa, MG, Brazil. e-mail: heraldo.pitanga@ ufv.br. Taciano Oliveira da Silva, D.Sc., Associate Professor, Departamento de Engenharia Civil, Universidade Federal de Viçosa, Viçosa, MG, Brazil. e-mail: taciano.silva@ ufv.br. Sérgio Leandro Scher Dias Neto, M.Sc., Departamento de Engenharia Civil, Universidade Federal de Viçosa, Viçosa, MG, Brazil. e-mail: sergio.scher.7@gmail.com. Dario Cardoso de Lima, Ph.D., Full Professor, Departamento de Engenharia Civil, Universidade Federal de Viçosa, Viçosa, MG, Brazil. e-mail: dclima@ ufv.br.

Tiago Pinto da Trindade, D.Sc., Process Coordinator, Companhia de Saneamento Ambiental do Distrito Federal, DF, Brazil. e-mail: tptrindade@ gmail.com. Submitted on August 7, 2019; Final Acceptance on May 26, 2020; Discussion open until September 30, 2020.

DOI: $10.28927 /$ SR.432271 
structure and, consequently, on soil engineering properties. Additionally, contributions from microscopic studies directed to the characterization of compacted tropical soils are welcome.

Studies on microscopic soil characterization have been carried out since the 1950s, gaining emphasis in the last three or four decades, and, over this time, techniques have been developed or improved to better characterize the structure and behavior of these materials. Among the methods applied to study the arrangement between individual particles and particle and pore clusters in natural or compacted soils, emphasis is given on the application of techniques of optical microscopy, electron microscopy, X-ray diffraction, mercury porosimetry and, more recently, computerized tomography (Mitchell \& Soga, 2005; Romero \& Simms, 2008).

In soil morphology studies, the use of the optical petrographic microscope is quite common. In optical microscopy, features such as fractured surfaces, silt-size particles or larger particles, aggregates of clay particles, preferential orientation of particles, homogeneity, pore size and distribution, and shearing zones can be observed (Bullock \& Murphy, 1980).

According to Crispim et al. (2011), these studies mainly recongnized three elements in the micromorphological description of soils: plasma, of colloidal size (about $10^{-6}$ to $10^{-9} \mathrm{~m}$ ), representing the material that can be moved by mechanical actions or by the action of water in the soil; and skeleton, formed by grains larger than colloidal; and pores, corresponding to the voids present in the soil. In the micromorphological study, from the analysis of fine sections, the soil constituents are recognized, observing the size, shape, arrangement, and orientation of the aggregates and the voids that separate them, as well as the relative distribution of the plasma in relation to the skeleton grains (Fitzpatrick, 1993). Stoops (2003) presents other more detailed and in-depth aspects of the morphological and microstructural characterization of soils. For Brazilian tropical soils, there are studies by Schaefer (2001), Viana et al. (2004), Trindade (2006), and Crispim et al. (2011).

In this framework and considering the geotechnical peculiarities of tropical soils, the objective of the present study was to evaluate the influence of the hydraulic gradient variation on the structure of a compacted tropical residual soil and, consequently, on its mechanical properties, represented by the shear strength. Simultaneously, the research aimed to highlight the importance of micromorphological analysis supported by statistics in understanding the structural aspects of compacted soils responsible for their engineering behaviors.

\section{Material}

A soil classified geotechnically as gneiss mature residual and, pedologically, as Red-Yellow Latosol (RYL) with great expressiveness in the Brazilian territory, and es- pecially in the Zona da Mata Norte of Minas Gerais, in the southeastern region of Brazil, was used throughout the study. Disturbed samples were collected in a borrow pit, located in the city of Viçosa, in the state of Minas Gerais, Brazil, at coordinates $20^{\circ} 45^{\prime} 35^{\prime \prime} \mathrm{S} ; 42^{\circ} 52^{\prime} 28^{\prime \prime} \mathrm{W}$.

The $\mathrm{pH}$ values of the soil, measured in water $\left[\mathrm{pH} \mathrm{H} \mathrm{H}_{2} \mathrm{O}\right.$ $(1: 2.5)=6.1]$ and in a solution of $\mathrm{KCl} 1 \mathrm{~mol} / \mathrm{L}[\mathrm{pH} \mathrm{KCl}$ $(1: 2.5)=5.96]$, allow to characterize it as slightly acidic. The cation exchange capacity is relatively low $(\mathrm{CEC}=2.09$ $\mathrm{cmol}_{\mathrm{c}} / \mathrm{kg}$ ) and compatible with the mineralogy of its clay fraction, which is predominantly composed of kaolinite and iron and aluminum oxides. Regarding the percentage base saturation (V \%), the soil presented a value of $52.6 \%$. According to Brady and Weil (1999), soils from tropical and wet regions, in which silicate clays predominate, are acidic when $\mathrm{V} \%$ is lower than $80 \%$. Therefore, the $\mathrm{V} \%$ value is in line with the $\mathrm{pH}$ value determined and with the clay minerals present in the studied soil.

A specific study was directed to the qualitative and semiquantitative determination of the presence of chemical elements in the soil using the microanalysis technique. The energy-dispersive X-ray spectroscopy (EDS) spectrum presented in Fig. 1 shows that the soil is basically constituted by $\mathrm{Al}, \mathrm{Si}$, and $\mathrm{Fe}$. The high amount of $\mathrm{Fe}$ found in the soil, a Red-Yellow Latosol, may be associated with the presence of goethite and the significant amounts of $\mathrm{Al}$ and $\mathrm{Si}$ probably related to the minerals kaolinite and quartz. The mineralogical analysis of soil samples allowed for the identification of the presence of quartz in the sand fraction (Fig. 2a), and of kaolinite, quartz, goethite, gibbsite, portlandite, and rankinite in the clay fraction (Fig. 2b).

The microstructure was characterized by an analysis of the secondary electron images obtained in Scanning Electron Microscope (SEM). Samples from soil compacted at the optimum conditions $\left(\mathrm{w}_{\mathrm{opt}}\right.$ and $\gamma_{d \max }$ ) of the standard Proctor test were analyzed. It was observed (Fig. 3) that the volume of soil analyzed was composed predominantly of plasma (compared to the skeleton) that formed a continuous phase and, in some cases, was presented in the form of spherical micro-aggregates joined together. These micro-

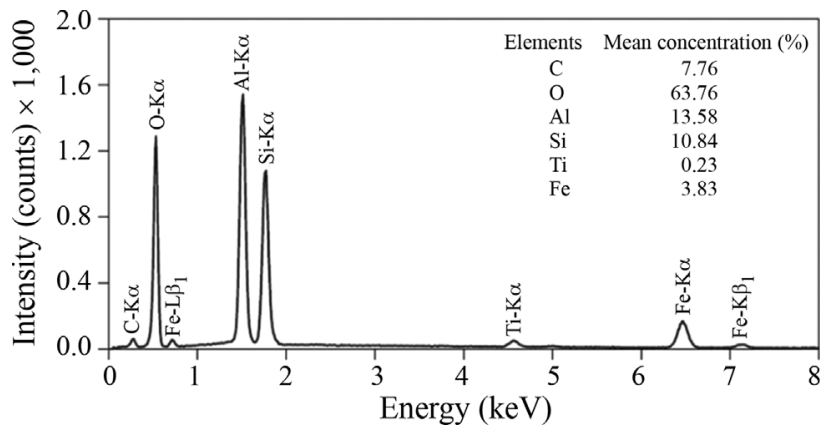

Figure 1 - EDS (Energy-dispersive X-ray spectroscopy) spectrum and mean concentration of chemical elements determined for the studied soil. 


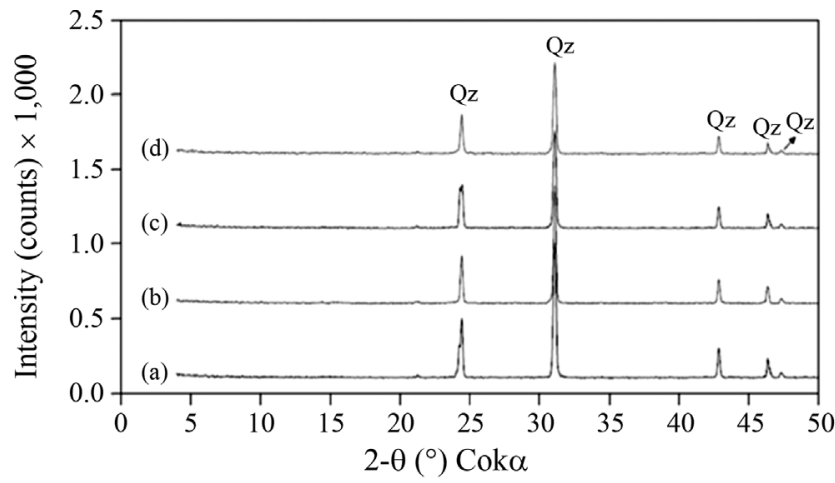

(a)

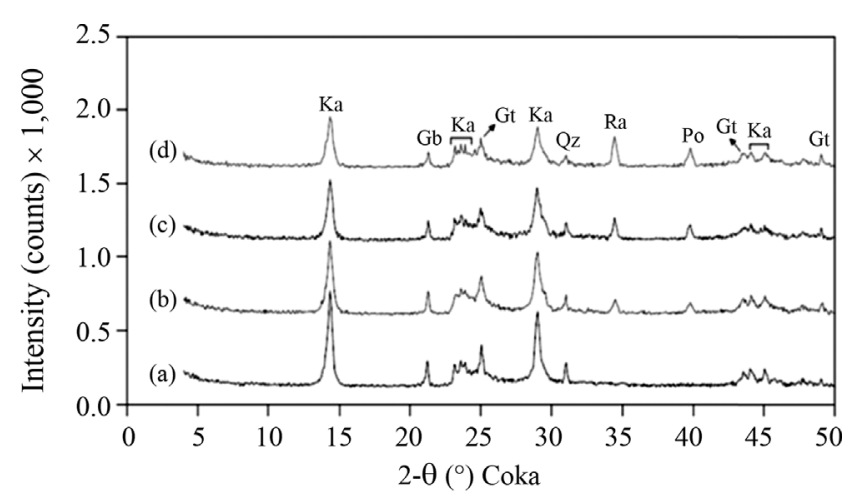

(b)

Figure 2 - Data from XRD (X-ray diffraction) analyses performed on soil samples: (a) XRD patterns of $\geq 53 \mu \mathrm{m}$ fraction of soil: $\mathrm{Qz}=$ quartz $\left[\mathrm{SiO}_{2}\right]$; (b) XRD patterns of $<53 \mu \mathrm{m}$ fraction of soil: $\mathrm{Gb}=$ gibbsite $\left[\mathrm{Al}(\mathrm{OH})_{3}\right]$, Gt $=$ goethite $[\alpha-\mathrm{FeO}(\mathrm{OH})], \mathrm{Ka}=\mathrm{kaolinite}$ $\left[\mathrm{Al}_{2} \mathrm{Si}_{2} \mathrm{O}_{5}(\mathrm{OH})_{4}\right], \mathrm{Po}=$ portlandite $\left[\mathrm{Ca}(\mathrm{OH})_{2}\right], \mathrm{Qz}=$ quartz $\left[\mathrm{SiO}_{2}\right]$ and $\mathrm{Ra}=$ rankinite $\left[\mathrm{Ca}_{3} \mathrm{Si}_{2} \mathrm{O}_{7}\right]$.

aggregates were formed by small-size particles, randomly placed, formed by aggregations of kaolinite and gibbsite minerals wrapped and cemented by iron oxyhydroxides responsible for the stability of their arrangement.

\section{Methods}

The compaction tests were carried out with the standard Proctor effort $\left(600 \mathrm{kN} . \mathrm{m} / \mathrm{m}^{3}\right)$, according to ABNT (2016), with limits for acceptance of soil samples related to the maximum dry unit weight of $\pm 0.30 \mathrm{kN} / \mathrm{m}^{3}$ and the optimum water content of $\pm 0.5 \%$. The soil samples were compacted dynamically into PVC cylinders in three layers, $12 \mathrm{~cm}$ high and $10 \mathrm{~cm}$ in diameter, so that after molding they could be used directly in the column percolation equipment, where they were subjected to upward percolation of deaerated and deionized water, in a room maintained at a constant temperature of $2{ }^{\circ} \mathrm{C} \pm 1{ }^{\circ} \mathrm{C}$, according to the guidelines in (ABNT, 2000) and (ABNT, 1995a).

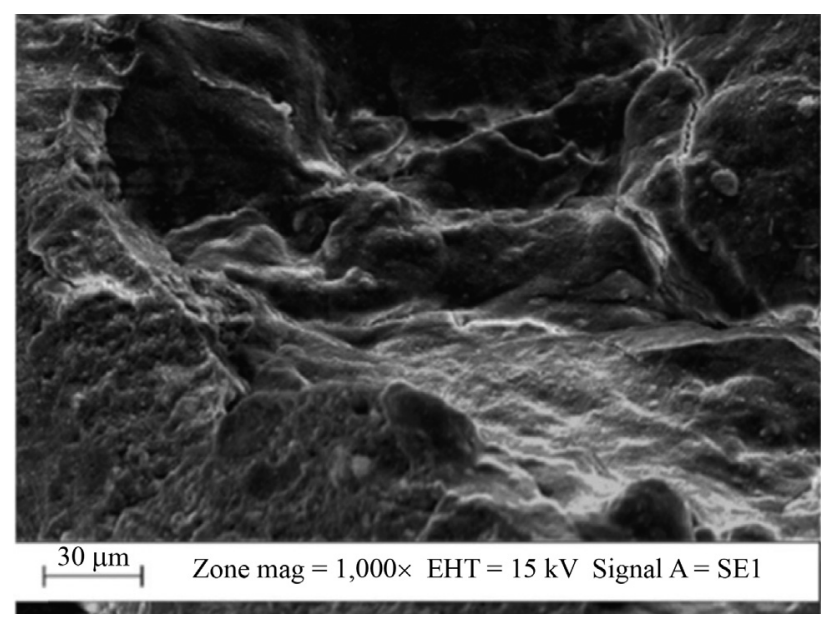

Figure 3 - Samples compacted at the standard Proctor effort images obtained by secondary electron signals produced in Scanning Electron Microscope (SEM).
In column percolation, hydraulic gradients (HG) of $15,66,85$, and 140 were applied until reaching constant flow in a set of four compacted cylindrical specimens for each HG. After column percolation test, for each hydraulic gradient, specimens were molded for direct shear test (three specimens) and micromorphological analysis (one specimen). Figure 4 shows a schematic sketch of extraction of soil samples for molding $6 \mathrm{~cm} \times 6 \mathrm{~cm} \times 2.5 \mathrm{~cm}$ specimens for direct shear test (ASTM, 2011).

After inundation with deaerated and deionized water for a period of two hours, aiming to eliminate the influence of the suction variable in the analysis, each soil specimen was consolidated and tested in the direct shear apparatus at the vertical stress of $100 \mathrm{kPa}$ and the horizontal displacement velocity of $0.15 \mathrm{~mm} / \mathrm{min}$. to determine the mean shear strength of each specimen layer (three determinations were used to calculate the mean shear strength).

In the micromorphological analysis, the fourth specimen subjected to column percolation under constant hydraulic gradient was used to extract two thin sections, respectively, from the top and bottom compacted layers (Figs. 5a and 5b). From these thin sections, microscopic images were obtained to analyze the pattern and microstructural composition of the compacted material. A similar procedure was applied to a compacted soil test specimen not subjected to water percolation (hydraulic gradient

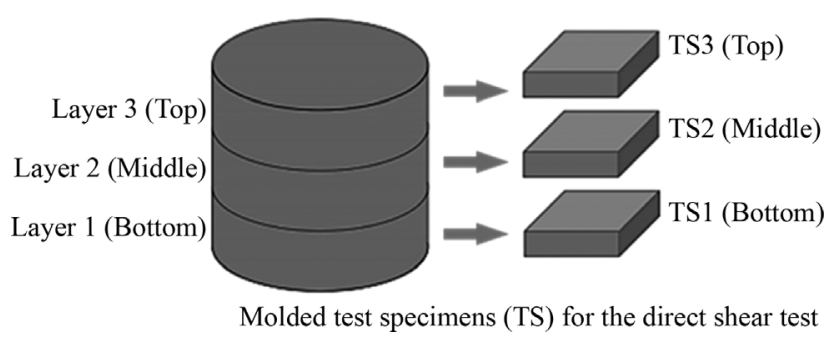

Figure 4 - Schematic sketch of soil samples extraction of each specimen already tested in the column percolation test. 
$\mathrm{HG}=0$ ), which served as a reference for structural comparison purposes. The protocol for preparation of the thin sections was adopted according to Crispim et al. (2011).

The photomicrographs obtained under an optical microscope were edited using Paint.NET image editing software (Brewster, 2014). Quantitative measurements of pores, plasma and grains were performed using ImageJ software (Schneider et al., 2012). In the analysis of the images, the micromorphological features were separated into three groups (Fig.5c), namely: quartz grains and opaque minerals, here called quartz grains (Grains Qz), corresponding to the soil skeleton; slits and vesicles, corresponding to the soil pores; and plasma. For the top and bottom thin sections, the mean percentages of the indentified features were obtanied from five microscope images.

A Complete Randomized Design (CRD) was used in the statistical analysis of the direct shear tests and micromorphological study data encompassing analysis of variance (ANOVA) at $5 \%$ probability, as follows:

(1) Results of the direct shear tests: differences between the means of the shear strength of each layer of the test specimens for each hydraulic gradient; differences between the means of the shear strength of each layer of the test specimens for all hydraulic gradients; and differences between the general means of shear strength determined for each hydraulic gradient; and

(2) Results of the micromorphological study: differences between the means of the micromorphological features of the top and bottom layers of the test specimen for the same hydraulic gradient; and differences between the means of the micromorphological features of each layer group for all hydraulic gradients.
Whenever significant differences were found, the means were compared by Tukey's test, at $5 \%$ probability.

\section{Results and Discussion}

\subsection{Geotechnical parameters of test specimens}

Table 1 lists the results of the soil geotechnical characterization, including Atterberg limits [liquid limit (LL), plastic limit (PL)] and plasticity index (PI), specific gravity of soil solids $\left(\gamma_{s}\right)$, particle-size distribution according to the scale adopted by ABNT (1995b), and optimum compaction parameters from the standard Proctor compaction procedure.

Table 2 presents the results of the post-molding mean geotechnical parameters of twelve test specimens subjected to the column percolation tests. The respective standard deviation values attest to the relative uniformity of the specimens prepared for the tests. The magnitude of their mean degree of saturation (DS) indicates that, before the column

Table 2 - Post-molding mean geotechnical parameters of all specimens used in the column percolation tests.

\begin{tabular}{lcc}
\hline $\begin{array}{l}\text { Geotechnical parameters of } \\
\text { the test specimens }\end{array}$ & Mean & $\begin{array}{c}\text { Standard } \\
\text { deviation }\end{array}$ \\
\hline Water content $(\%)$ & 31.35 & 0.365 \\
Dry unit weight $\left(\mathrm{kN} / \mathrm{m}^{3}\right)$ & 14.05 & 0.061 \\
Void ratio & 0.941 & 0.009 \\
Porosity (\%) & 48.47 & 0.224 \\
Degree of compaction $(\%)$ & 103.03 & 0.477 \\
Degree of saturation $(\%)$ & 92.83 & 1.146 \\
\hline
\end{tabular}

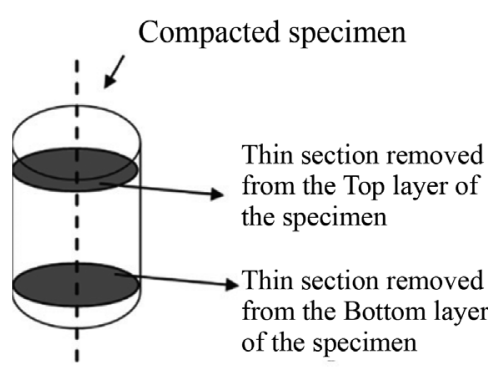

(a)

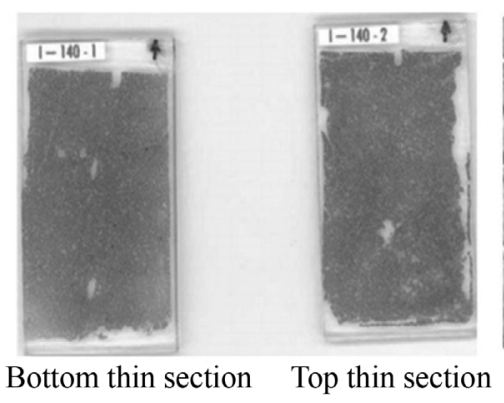

(b)

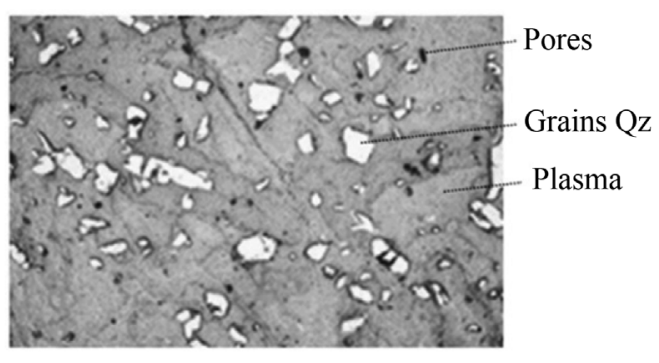

(c)

Figure 5 - Micromorphological analysis: (a) schematic diagram indicating the region of removal of the thin soil sections; (b) sections to be analyzed; (c) micromorphological aspects of soil subjected to quantification in ImageJ software.

Table 1 - Results of the geotechnical characterization of the RYL soil sample.

\begin{tabular}{|c|c|c|c|c|c|c|c|c|}
\hline \multicolumn{3}{|c|}{ Atterberg limits and plasticity index } & \multirow[t]{2}{*}{$\gamma_{s}\left(\mathrm{kN} \cdot \mathrm{m}^{-3}\right)$} & \multicolumn{3}{|c|}{ Particle size distribution } & \multirow[t]{2}{*}{$\mathrm{W}_{\mathrm{opt}}(\%)$} & \multirow[t]{2}{*}{$\gamma_{d \max }\left(\mathrm{kN} \cdot \mathrm{m}^{-3}\right)$} \\
\hline $\operatorname{LL}(\%)$ & PL $(\%)$ & PI $(\%)$ & & Sand $(\%)$ & Silt $(\%)$ & Clay $(\%)$ & & \\
\hline 82 & 46 & 36 & 27.27 & 23 & 10 & 67 & 31.37 & 13.54 \\
\hline
\end{tabular}

Note: PI $(\%)=\operatorname{LL}(\%)-$ PL $(\%)$. 
percolation tests, they were physically close to the saturated condition (DS $=100 \%$ ), which was probably reached during the tests, when the constancy condition of the water flow was reached.

\subsection{Direct shear tests}

Figure 6 presents the overall mean of all shear strength measurements obtained and the means per layer of the specimens for each hydraulic gradient.

From the geotechnical point of view, based on the results in Fig. 6, there is an upward trend for the mean shear strength from the bottom layer to the top layer of the test specimens, although of small magnitude, with values of the order of $6 \mathrm{kPa}$ for the hydraulic gradient 15, and $7 \mathrm{kPa}$ for the hydraulic gradient 66 . However, for the hydraulic gradients 85 and 140, an opposite behavior is observed, noticing a decrease in the shear strength from the bottom to the top, of the order of $6 \mathrm{kPa}$ and $13 \mathrm{kPa}$, respectively. Thus, there are two distinct responses in the mean shear strength values of the layers, respectively, for the hydraulic gradient sets 15-66 and 85-140. In addition, based on data from Figs. $6 \mathrm{~b}$ and $6 \mathrm{c}$, and for practical geotechnical engineering purposes:

(1) There is a slight superiority, of the order from $8 \mathrm{kPa}$ to $9 \mathrm{kPa}$, in the overall mean of the shear strength related to the hydraulic gradient 15 in comparison to the others, and there is no difference between the results obtained for the gradients 66, 85 and 140; and

(2) There is significant variation in the means of shear strength of the top layer of the tested specimens between the hydraulic gradients 15 and 140, which is of the order of $+20 \mathrm{kPa}$; however, based on the results concerning the middle and the bottom of the specimens, there are minor variations between the referred hydraulic gradients, respectively, of the order of + $11 \mathrm{kPa}$ and $+0.6 \mathrm{kPa}$.

On the other hand, at the $5 \%$ probability level, the results of the statistical analyses evidence that:

(1) There is no significant difference in the means of shear strength determined in the top, middle and bottom layers of the tested specimens for each hydraulic gradient analyzed;

(2) There is no significant variation in the means of the shear strength of each layer considering all hydraulic gradients tested; and

(3) There is no significant contrast in the overall means of the shear strength of the tested specimens for the same hydraulic gradient.

\subsection{Micromorphological analysis}

From Fig. 7, optical microscopy images show the relative distribution between skeleton and plasma, classified as porphyric according to Stoops (2003), with the distribution of larger particles in a soil matrix of much smaller particles.

From the micromorphological analysis, there is an almost complete loss of the packing pores in the compacted material, forming a structure with unconnected voids in the shape of stars, densified at the edges. Loss of most of the medium and large porosity occurs, forming an unconnected network of cracks and voids along the planes of intergranular adjustments, composing a new network of voids that do not favor infiltrability. Also, the structure resulting from the compaction of the smaller soil particles is composed predominantly of plasma when compared to the other identifiable features (Grains Qz and soil pores).

Regarding all hydraulic gradients tested and considering the bottom and top positions of the specimens tested, Figs. 8 and 9 show, respectively, the mean percentages of the areas of features Grains Qz, pores, and plasma together, and the same percentages for each of these features separately.

The data show that, regardless of the hydraulic gradient adopted in the column percolation tests, there were no relevant percentage changes, at the base and at the top of the test specimens, for the quartz grains, porosity and plasma, compared to the structure of the non-percolated specimens. This experimental evidence applies when comparing such structural aspects at the base and top for the same hydraulic gradient, or when considering all the hydraulic gra-

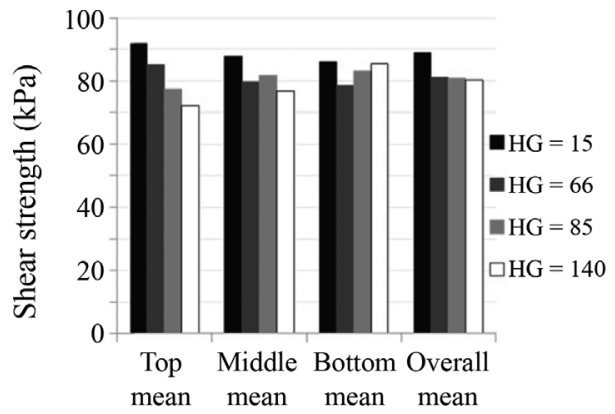

(a)

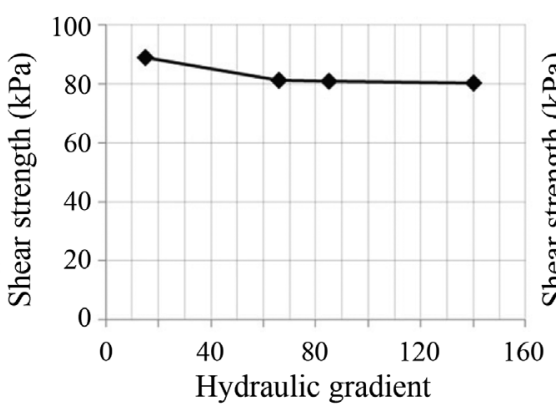

(b)

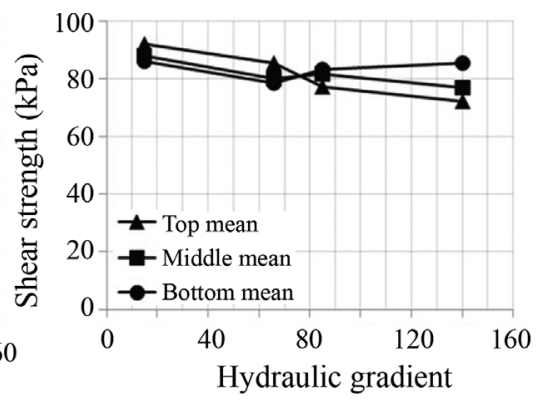

(c)

Figure 6 - Results of the shear strength tests: (a) comparison between the overall mean and the means per layer considering the hydraulic gradients analyzed; (b) overall mean shear strength; (c) mean shear strength per layer. 
dients considered in the study. Although there is a tendency of differentiation between the base and the top for the porosity (Figs. 9c and 9d), it is verified that this distinction oc-

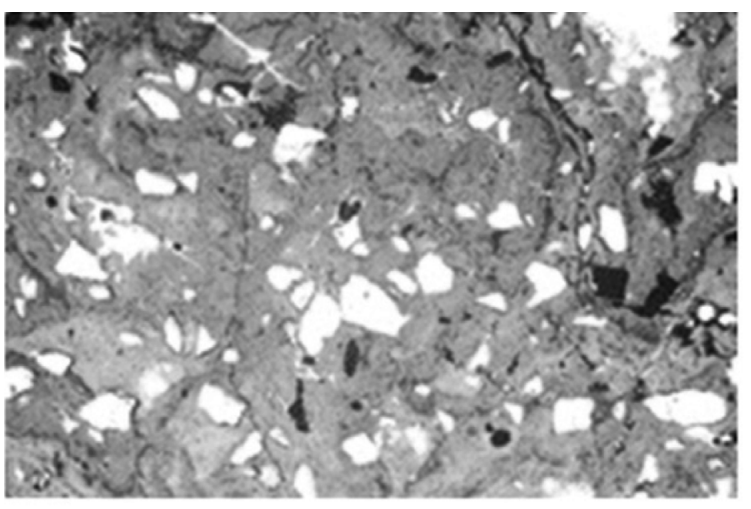

(a) curs in a percentage range that is effectively restricted and of low magnitude (minimum of $0.59 \%$, maximum of $1.68 \%)$.

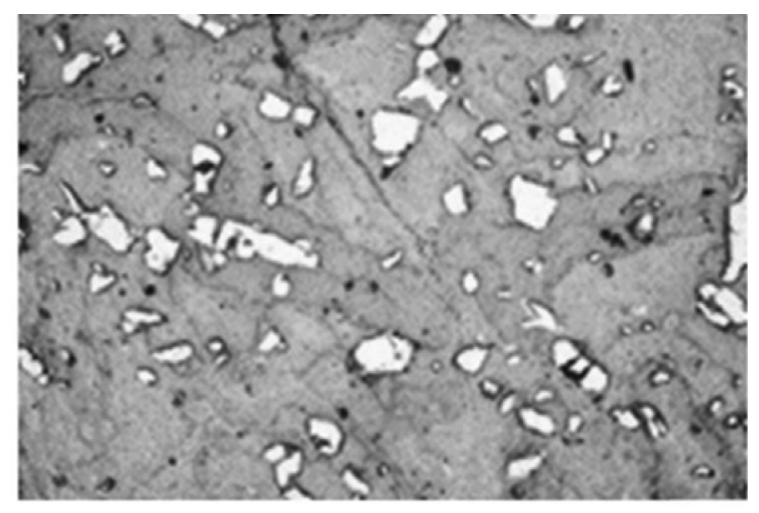

(b)

Figure 7 - Samples of optical microscopy images of thin sections of the soil tested specimens: (a) top thin section; (b) bottom thin section.

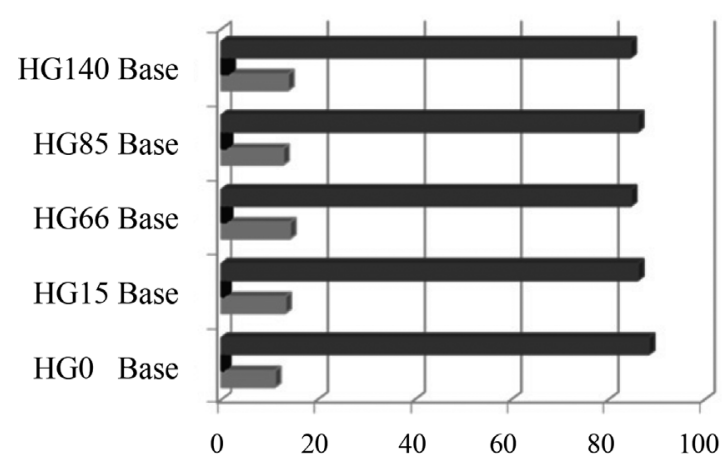

(a)

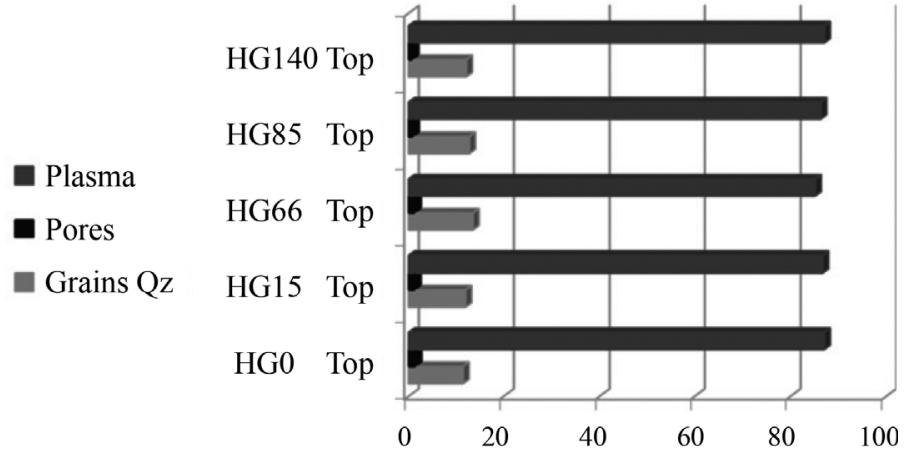

(b)

Figure 8 - Joint graphical representation of the mean percentages of the areas of features Grains Qz, pores and plasma on the bottom and top positions of specimens, for all hydraulic gradients: (a) at the bottom of the specimens; (b) at the top of the specimens.

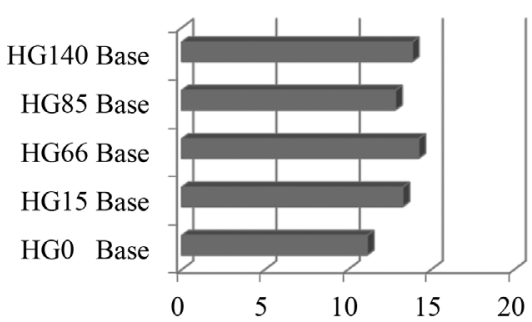

(a)

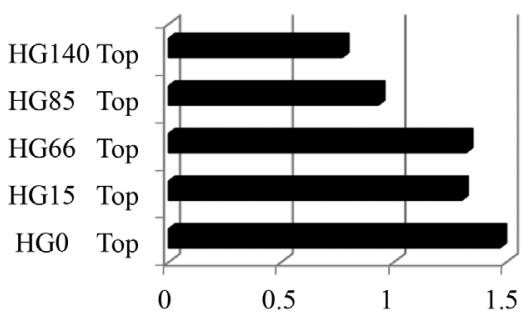

(d)

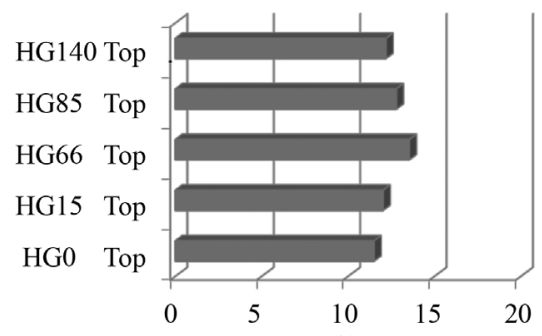

(b)

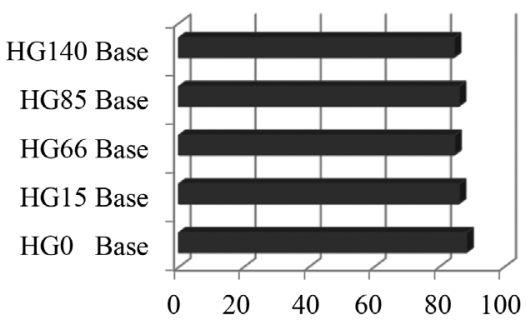

(e)

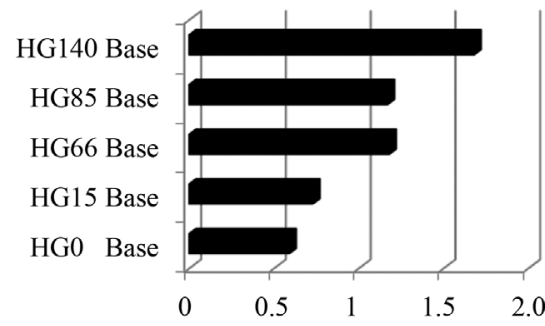

(c)

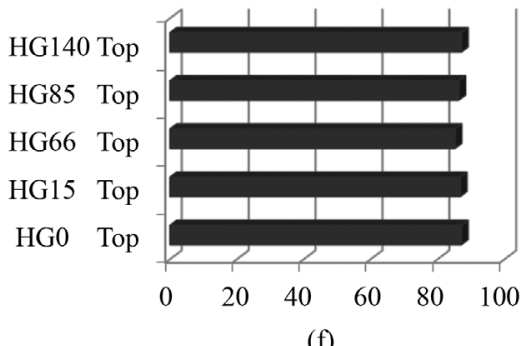

(f)

Figure 9 - Separate graphic representations of the mean percentages of features Qz Grains, pores and plasma on the bottom and top positions of specimens, for all hydraulic gradients: (a) Qz Grains at the bottom (b) and the top; (c) Pores at the bottom and (d) the top; (e) Plasma at the bottom (e) and the top (f). 


\section{Conclusions}

Based on the results obtained, for the particularities of the present study and the soil in the compacted state, it is concluded that: (1) under the geotechnical perspective, it is possible that there is a slight downward trend in the general mean of the shear strength with the elevation in the hydraulic gradient; (2) there is no significant variation in the shear strength means determined in the top, middle and bottom layers of the specimens, regarding the results of the direct shear tests, for each hydraulic gradient analyzed, no significant variation was observed between the shear strength means of each layer, considering all hydraulic gradients, and there was no significant difference between the overall shear strength means of the specimens with the variation in the hydraulic gradient; and (3) statistically, at the $5 \%$ probability level, the results of the micromorphological analysis show that there is no significant variation in the micromorphological features of the porosity, quartz grains, and plasma as a function of the hydraulic gradient used in the tests. The soil structural stability under variations in the water percolation conditions suggests that the compacted tropical soil would offer good functional performance in hydraulic barriers or landfills. It is also assumed that the geotechnical peculiarities of the compacted soil are responsible for its structural stability. Special emphasis is given to micromorphological analysis supported by statistics in understanding the structural aspects of compacted soils responsible for their engineering behavior.

\section{Acknowledgments}

The authors acknowledge the financial support by the Coordinating Agency for Advanced Training of Graduate Personnel (CAPES).

\section{References}

ABNT (1995a). Soil - Determination of the Coefficient of Permeability of Granular Soil by Constant-Head. Test Method. NBR 13292. Rio de Janeiro, Brazil, 8 p. (In Portuguese).

ABNT (1995b). Rocks and Soils. Terminology. NBR 6502. Rio de Janeiro, Brazil, 18 p. (In Portuguese).

ABNT (1996). Introduction of Projects for Sanitary Filling of Urban Solid Wastes. Procedure. NBR 8419. Rio de Janeiro, Brazil, 7 p. (In Portuguese).

ABNT (2000). Soil - Determination of the Coefficient of Permeability of Clay Soils. NBR 14545. Rio de Janeiro, Brazil, 12 p. (In Portuguese).

ABNT (2016). Soil - Compaction Test. NBR 7182. Rio de Janeiro, Brazil, 9 p. (In Portuguese).

Al-Taie, L.; Pusch, R. \& Knutsson, S. (2014). Hydraulic properties of smectite rich clay controlled by hydraulic gradients and filter types. Applied Clay Science, 87:73-80. DOI: 10.1016/j.clay.2013.11.027.
ASTM (2011). Standard Test Method for Direct Shear Test of Soils under Consolidated Drained Conditions. D3080/D3080M-11. ASTM International, West Conshohocken, PA, USA, 9 p.

Bello, A.A. (2011). Analysis of shear strength of compacted lateritic soils. Pacific Journal of Science and Technology, 12(1):425-433.

Benson, C.H.; Zhai, H. \& Wang, X. (1994). Estimating hydraulic conductivity of compacted clay liners. Journal of Geotechnical Engineering, 12(1):366-387. DOI: 10.1061/(ASCE)0733-9410(1994)120:2(366).

Benatti, J.C.B.; Rodrigues, R.A. \& Miguel, M.G. (2013). Aspects of mechanical behavior and modeling of a tropical unsaturated Soil. Geotechnical and Geological Engineering, 31(4):1569-1585. DOI: 10.1007/s10706-013-9682-y.

Brewster, R. (2014). Paint.NET. Version 4.0. dotPDN LLC.

Brady, N.C. \& Weil, R.R. (1999). The Nature and Property of Soils. Prentice Hall, Upper Saddle River, 960 p.

Bullock, P. \& Murphy, C.P. (1980). Towards the quantification of soil structure. Journal of Microscopy, 120(3):317-328.

DOI: 10.1111/j.1365-2818.1980.tb04151.x.

Crispim, F.A.; Lima, D.C.; Schaefer, C.E.G.R.; Silva, C.H.C.; Carvalho, C.A.B.; Barbosa, P.S.A. \& Brandão, E.H. (2011). The influence of laboratory compaction methods on soil structure: Mechanical and micromorphological analyses. Soils and Rocks, 34(1):91-98.

Daniel, D.E. \& Wu, Y.K. (1993). Compacted clay liners and covers for arid sites. Journal of Geotechnical Engineering, 199(2):223-237. DOI: 10.1061/(ASCE)0733-9410(1993)119:2(223).

Fitzpatrick, E.A. (1993). Soil Microscopy and Micromorphology. John Wiley \& Sons, New York, 304 p.

Fox, P. (1996). Analysis of hydraulic gradient effects for laboratory hydraulic conductivity testing. Geotechnical Testing Journal, 19(2):181-190. DOI: 10.1520/GTJ10340J.

Frempong, E.M. \& Yanful, E.K. (2008). Interactions between three tropical soils and municipal solid waste landfill leachate. Journal of Geotechnical and Geoenvironmental Engineering, 134(3):379-396. DOI: 10.1061/(ASCE)1090-0241(2008)134:3(379).

Galvão, T.C.B.; Elsharief, A. \& Simões, G.F. (2004). Effects of hydrated lime on permeability and compressibility of two tropical residual soils. Journal of Environmental Engineering, 130(8):881-885. DOI: 10.1061/(ASCE)0733-9372(2004)130:8(881).

Kaoser, S.; Barrington, S.; Elektorowicz, M. \& Ayadat, T. (2006). The influence of hydraulic gradient and rate of erosion on hydraulic conductivity of sand-bentonite mixtures. Soil and Sediment Contamination: An International Journal, 15(5):481-496. DOI: $10.1080 / 15320380600847815$. 
Ke, L. \& Takahashi, A. (2012). Strength reduction of cohesionless soil due to internal erosion induced by onedimensional upward seepage flow. Soils and Foundations, 52(4):698-711. DOI: 10.1016/j.sandf.2012.07.010.

Ke, L. \& Takahashi, A. (2014). Experimental investigations on suffusion characteristics and its mechanical consequences on saturated cohesionless soil. Soils and Foundations, 54(4):713-730. DOI: 10.1016/j.sandf.2014.06.024.

Kundiri, A.M.; Muhammed, A.S. \& Abah, G. (2016). Effect of compactive efforts on desiccation - Induced volumetric shrinkage strain of some compacted tropical soils. Malaysian Journal of Civil Engineering, 28(2):284-299.

Mitchell, J.K. \& Soga, K. (2005). Fundamentals of Soil Behavior. Wiley, Chichester, 577 p.

Ola, S.A. (1980). Permeability of three compacted tropical soils. Quarterly Journal of Engineering Geology and Hydrogeology, 13(2):87-95. DOI: 10.1144/GSL.QJEG.1980.013.02.03.

Osinubi, K.J. \& Nwaiwu, C.M. (2006). Design of compacted lateritic soil liners and covers. Journal of Geotechnical and Geoenvironmental Engineering, 132(2):203-213.

DOI: 10.1061/(ASCE)1090-0241(2006)132:2(203).

Romero, E. \& Simms, P.H. (2008). Microstructure investigation in unsaturated soils: A review with special attention to contribution of mercury intrusion porosimetry and environmental scanning electron microscopy. Geotechnical and Geological Engineering, 26(6):705-27. DOI: 10.1007/s10706-008-9204-5.
Schaefer, C.E.R. (2001). Brazilian latosols and their B horizon microstructure as long-term biotic constructs. Australian Journal of Soil Research, 39(5):909-926. DOI: 10.1071/SR00093.

Schneider, C.A.; Rasband, W.S. \& Eliceiri, K.W. (2012). NIH Image to ImageJ: 25 years of image analysis. Nature Methods, 9(7):671-675. DOI: 10.1038/nmeth.2089.

Stoops, G. (2003). Guidelines for Analysis and Description of Soil and Regolith Thin Section. Soil Science Society of America, Madison, $184 \mathrm{p}$.

Taha, M.R. \& Kabir, M.H. (2005). Tropical residual soil as compacted soil liners. Environmental Geology, 47(3):375-381. DOI: 10.1007/s00254-004-1160-7.

Trindade, T.P. (2006). Technological Characterization of Residual Soils Chemically Stabilized for Highway and Environmental Geotechnical Applications. Ph.D Dissertation, Departamento de Engenharia Civil, Universidade Federal de Viçosa, Viçosa, 254 p. (In Portuguese).

Viana, J.H.M.; Fernandes Filho, E.I. \& Schaefer, C.E.G.R. (2004). Effects of wetting and drying cycles on the reorganization of the microgranular structure of latosols. Revista Brasileira de Ciência do Solo, 28(1):1-19 (In Portuguese).

DOI: 10.1590/S0100-06832004000100002.

Vertematti, J.C. (2015). Brazilian Manual of Geosynthetics. Edgard Blucher, São Paulo, 576 p. (In Portuguese).

Wesley, L.D. (1990). Influence of structure and composition on residual soils. Journal of Geotechnical Engineering, 116(4):589-603. DOI: 10.1061/(ASCE)0733-9410(1990)116:4(589). 